\title{
PRISON VIOLENCE: PERSPECTIVES AND EPIDEMIOLOGY
}

\section{Tony Butler and Azar Kariminia}

Centre for Health Research in Criminal Justice, NSW Justice Health

and

School of Public Health and Community Medicine, University of New South Wales

Violent crime receives considerable media attention. Its importance to the community is such that it is used as a yardstick against which to judge the effectiveness of social policy and the performance of governments. Programs and interventions to reduce violence and its consequences are needed given the level of community concern and the impact violence has on both the victim and society. Many of those who commit violent crimes receive custodial sentences and spend prolonged periods behind bars. Violence in prison presents a challenge to custodial authorities because of the risk of injury to prisoners and staff, and the impact violence has on the provision of services, staffing, contact between inmates, and rehabilitation. In this article we present the rates of violent crime in Australia, NSW and within NSW prisons. We also outline some of the major theories that seek to explain violence in prisons, and discuss the difficulties in recording violence within prisons. Recent findings from the Prison Injury Surveillance Program by Justice Health are also presented.

\section{CRIME IN AUSTRALIA}

The latest Australian crime data reported 197,612 violent acts (homicide, assault, sexual assault, robbery, and kidnapping) for 2003, an increase of 35 per cent from 145,902 in $1996 .{ }^{1}$ Assaults account for most (80 per cent) of these incidents. During the same period, the national rate of crime per 100,000 adults increased by 53 per cent (from 740 to 1130 ), assault increased by 23 per cent (from 652 to 804), sexual assault was up by 11 per cent (from 83 to 92) and robbery rose by 6 per cent (from 94 to 100). Homicide, however, fell 15 per cent (from 2.0 to 1.7).

Comparing rates of violent crime across international jurisdictions is difficult, mainly because of the use of different recording methods. However, one comparison of criminal justice statistics from 39 countries ranked Australia in the middle-range with respect to both the number of crimes and the increasing trend. ${ }^{2}$ A comparison of crime rates during 1996-2003 with three other industrialised nations reveals Australia had the second worst violent crime rate after the United Kingdom. During this period Australia and the United Kingdom had an increasing rate of violent crime, while Canada and the United States had a falling rate. ${ }^{3}$

The full-time Australian prison inmate population in 2005 was 25,353 , with approximately 35 per cent held in NSW prisons. ${ }^{4}$ Despite an observed increase in the rate of violent crime, the proportion of prisoners charged with, or convicted of, a violent crime has remained unchanged since 1996 at around 47 per cent. Repeat offenders comprise a large proportion of the prisoner population. In NSW, for instance, 44 per cent of prisoners released in 2002-03 returned to prison within two years. ${ }^{5}$ Prisoners released from a term of imprisonment for assault and robbery have the highest rate of return to custody.

\section{PERSPECTIVES ON PRISON VIOLENCE}

Criminal behaviour often continues during incarceration. Studies show that inmate misconduct, inmate - correctional officer discord, prison gang violence, and rioting occur even in well managed correctional facilities. Nevertheless, most empirical data indicates lower rates of violence in prison than on the streets, even when prisons are compared with the high crime rate districts from which offenders are drawn. An inmate from a maximum security prison in the United States provided the following insight:

'If you expect the usual prison tale of constant violence, brutal guards, gang rapes, daily escape efforts, turmoil, and fearsome adventure, you will be disappointed. Prison life is really nothing like what the press, television, and movies suggest. It is not a daily round of threats, fights, plots, and "shanks"- though you have to be constantly careful to avoid situations or behaviour that might lead to violence. A sense of impending danger is always with you; you must be careful to move around people rather than against or through them, but with care and reasonable sense you can move safely enough. For me and many like me in prison, violence is not the major problem; the major problem is monotony. ${ }^{6}$

Penologists attempt to explain inmate misconduct and violence in terms of 'importation' and 'deprivation' theories: the former centres on violent inmates while the latter portrays inmate violence as a product of the prison milieu. Both theories are based on broader cultural and structural perspectives that have been developed by sociologists to explain patterns of violence in the broader society.

Most of the literature on prison violence deals with the characteristics of the prisoner population. The 'importation' or 'cultural' model attributes inmate conduct to the influence of pre-prison identities, values, and experiences. ${ }^{7.8}$ Factors that correlate with violence are common in prisoner populations - a young, predominantly male environment, low socio-economic status, histories of abuse and neglect, poor educational attainment, unemployment, social isolation, interpersonal conflicts, financial dependence, mental illness and substance abuse.

Age is one of the best predictors of prison violence. ${ }^{9}$ Younger inmates are volatile, more resistant to prison 
officials, and more likely to be involved in violent acts. One study from the United States described the violence-related misconduct of inmates in a large state prison. The authors identified the following offender groups: 'innocents' (no prison violence), 'once only offenders', 'minor recidivists' (2-4 violations), 'chronic offenders' (5-29 prison offences), and 'extreme chronic offenders' (30+ prison offences). According to the author a small cadre of inmates accounted for 100 per cent of the homicides, 75 per cent of the rapes, 80 per cent of the arsons, and 50 per cent of the aggravated assaults occurring behind bars. ${ }^{10}$

The 'deprivation' or 'prisonisation' model, on the other hand, provides a structural explanation that views inmate behaviour as a response to the stressful and oppressive conditions within the prison itself. Prison specific characteristics such as crowding, visiting patterns, involvement in prison programs, and rule enforcement are all related to prison violence. ${ }^{11,12}$ Such deprivations may provide some inmates with an incentive for the exploitation and predation of other inmates as a means of reducing the pain of imprisonment. ${ }^{13}$

While these two perspectives offer valid arguments for explaining prison violence, neither model alone can adequately predict inmate misconduct. As Porporino and Zamble ${ }^{14}$ suggest, 'Generally speaking, there are few attitudinal or behavioural dispositions that are so powerful as to totally determine actions in all situations, and few environmental events which can compel identical responses from people with varying dispositions. We would expect that the interaction between the individual and his environment would be the most powerful determinant of behaviour'.

\section{NEUROPSYCHIATRIC FACTORS IN VIOLENT BEHAVIOUR}

Recently, attention has focused on examining the role of neuropsychiatric factors in violent behaviour among offender populations. Indeed, the link between impulsivity and offending has long been established in the criminology literature. Heilbrun developed a rating scale to classify offences based on independent assessments of police reports. ${ }^{15}$ Violent crimes (manslaughter, murder, assault and rape) were more likely to be classified as impulsive while non-violent crimes (arson and forgery) were the least impulsive offences.

Impulsive aggression is a common complication of traumatic brain injury (TBI), reflecting the special vulnerability of frontal lobe structures to trauma. Although persistent sequelae are more common with increasing severity of TBI, even a single, apparently mild TBI may be associated with neuropathological abnormalities and ongoing behavioural and/or cognitive impairments. ${ }^{16,17} \mathrm{~A}$ number of studies suggest a link between TBI and offending behaviour. $^{18}$
Following reports from prison health staff that many prisoners appeared to have histories of TBI, we examined neuropsychiatric factors in two studies. Firstly, the 2001 NSW Inmate Health Survey found that over 45 per cent of prisoners reported sustaining a head injury resulting in a loss of consciousness. ${ }^{19}$ Being struck by an object or person (a euphemism for assault) was the most common cause of the head injury (60 per cent). This work was expanded in the Hunter Area where it was found that 80 per cent of detainees entering the criminal justice system had experienced a TBI sufficient to cause at least transient confusion at some time in the past, and 65 per cent reported a head injury associated with loss of consciousness. These findings suggest that biological factors have an important role to play in offending behaviour but require further investigation to support the biological perspective.

One intriguing study undertaken at a young offender institution in the United Kingdom ${ }^{20}$ found that supplementing inmates' diets with vitamins, minerals, and fatty acids resulted in a 26 per cent reduction in disciplinary incidents (including violence) in the inmates given supplements compared with those receiving placebos. The control group showed little change in antisocial behaviour. Hibbeln ${ }^{21}$ published a study entitled Seafood consumption and homicide mortality and found a remarkable correlation between a higher intake of omega- 3 fatty acids (most often obtained from fish) and lower murder rates. These studies and the evidence mentioned above support the notion that brain metabolism has a role to play in violent behaviour.

\section{RECORDING VIOLENCE IN PRISON}

Overall, serious violence-related misconduct is relatively infrequent in prison. In a study on a probability sample of 1,005 inmates in the United States ${ }^{10}$, with the exception of simple assault (14 per cent), threatening staff (12.5 per cent), and weapons possession (12 per cent), most inmates were not involved in serious offences. Indeed, the prevalence for aggravated assault (8.6 per cent), rioting (5.4 per cent), arson ( 2.1 per cent), rape ( 0.4 per cent), and homicide ( 0.3 per cent) were low. In this study, minor recidivists, chronic offenders and extreme chronic offenders made up 16 per cent, 33 per cent and 8 per cent respectively of the inmate population.

Using data from the United States Federal prisoner population for 1991-1998, Harrer and Langan ${ }^{22}$ found the rate of serious violent misconduct (murder/attempted murder, serious assault, and weapons possession) during the first year in prison to be 0.71 per 100 in men, while less serious violent misconduct (fighting, bodily harm, less serious assault) was 4.56 per 100 men. For women, the comparable rates were 0.08 per 100 for serious violent misconduct and 2.53 per 100 for less serious violent misconduct.

According to a 2001 NSW Department of Corrective Services report ${ }^{23}$, there was a rate of 14.7 per hundred 
inmates for prisoner-prisoner assaults causing non-serious injuries and a rate of 2.8 per hundred inmates involving minor injuries. Maximum and medium security prisons were found to have a much higher rate of assaults than minimum security facilities $(25.6,22.0$ and 9.5 per hundred inmates respectively).

Reporting violence in prison through official channels is difficult. Recorded incidents grossly underestimate the actual level of institutional violence, particularly among certain groups (for example women). It is also recognised that some groups are under greater scrutiny from the authorities and are therefore over-represented in official reporting systems. Perpetrators often invite punitive retribution from the authorities and victims incur the wrath of fellow inmates for violating the prisoners' code of silence. To overcome this, Hewitt ${ }^{24}$ used a questionnairebased approach comparing inmates' self-reported violations with prison guards' observations of rule violations and those documented in official records. He found that:

- Inmates were more extensively involved in misconduct than is presumed from official records.

- Guards observed nearly as many acts of misconduct as admitted by inmates, but reported very few of them.

- The findings bore little relationship to the sex or race of inmates.

\section{NSW PRISON INJURY SURVEILLANCE}

The European Committee for the Prevention of Torture and Inhuman or Degrading Treatment or Punishment has recommended that "prison health care services can contribute to the prevention of violence against detained persons, through the systematic recording of injuries' ${ }^{25}$ To this end, NSW Justice Health established a pilot surveillance project in 2002 to examine injury presentations to the prison clinics. ${ }^{26}$ Assaults were the second most common injury treated by the prison nurses ( 24 per cent of all injuries). They were most often associated with injuries to the eyes (26 per cent), head ( 21 per cent) and face (18 per cent). The value of injury surveillance is seen in the rich information it yields and the potential for this to inform the development of interventions to reduce violence. For example, we identified that assaults occurred in similar proportions in both violent (homicide, sexual, robbery, assault) and nonviolent (property, driving, fraud, drugs, order breaches) offenders and were more common on Sundays. Fifty-three per cent of injuries reported on Sundays were intentional compared with a weekday average of 23 per cent. Sunday is a day traditionally reserved for family visits. This surveillance system has now been expanded to seventeen correctional facilities across NSW.

\section{SUMMARY}

Many prisoners have histories of exposure to inter-personal violence and continue to be at risk of further violence during incarceration. Programs to reduce violence during imprisonment are needed, as are interventions that reduce violent offending on release from prison. Preventing assaults and violence in prison may be difficult given the nature of the correctional environment and some of the possible causes of violent behaviour. Criminology is replete with well intentioned programs based largely on sociological theories with limited evidence to support them. There is a trend towards taking process evaluation and qualitative feedback as evidence in support of a program rather than utilising more rigorous studies that generate higher levels of evidence. Many of these programs ultimately fail. It is likely that successful interventions will require a multi-disciplinary approach taking into account personal, environmental and biological factors. In addition, reliable and accurate injury surveillance systems are necessary to detect broad trends in violence within prisons.

\section{REFERENCES}

1. Australian Institute of Criminology. Australian crime, facts \& figures. Canberra: AIC, 2005.

2. Barclay G, Tavares C, Sally K, Siddique A, Wilby E. International comparisons of criminal justice statistics. No: 12. 2001. London: Home Office, 2003.

3. Australian Institute of Criminology. Comparing international trends in recorded violent crime. Crime Facts Info 2006. Available from: www.aic.gov.au/publications/cfi/cfi115. html.

4. Australian Bureau of Statistics. Prisoners in Australia. (Catalog No: 4517.0). Canberra: Australian Bureau of Statistics, 2005.

5. Steering Committee for the Review of Government Service Provision. Review of Government Service Provision. Melbourne: Australian Government Productivity Commission, 2006.

6. Morris N. The contemporary prison. In: Morris N, Rothman DJ, editors. Oxford history of the prison. The practice of punishment in western society. New York: Oxford University Press, 1995: 227-59.

7. Harer MD. Race and prison violence. Criminology 1996; 34(3): 323-55.

8. Irwin J. Thieves, convicts, and the inmate culture. Soc Probl 1962; 10: 142-55.

9. Craddock A. A comparative study of male and female prison misconduct careers. The Prison Journal 1996; 76(1): 60-80.

10. DeLisi M. Criminal careers behind bars. Behavioral Science and the Law 2003; 21: 653-69.

11. Gaes GG, McGuire WJ. Prison violence: The contribution of crowding versus other determinants of prison assault rates. Journal of Research in Crime and Delinquency 2006; 22(1): 41-65.

12. Light SC. The severity of assaults on prison officers: A contextual analysis. Soc Sci Q 1990; 71: 267-84.

13. Poole ED, Regoli RM. Violence in juvenile institution. American Society of Criminology 1983; 21(2): 213-32.

14. Porporino F, Zamble E. Coping with imprisonment. Can J Criminol 1984; 26: 403-22.

15. Heilbrun AB. Psychopathy and violent crime. J Consult Clin Psychol 1979; 47: 509-16. 
16. Barth JT, Macciocchi SN, Giordani B, Rimel R, Jane JA, Boll TJ. Neuropsychological sequelae of minor head injury. Neurosurgery 1983; 13: 529-33.

17. Bigler ED. Neuropsychological results and neuropathological findings at autopsy in a case of mild traumatic brain injury. $J$ Clin Exp Neuropsychol 2004; 10: 794-806.

18. Freedman D, Hemenway D. Precursors of lethal violence: a death row sample. Soc Sci Med 2000; 50: 1757-70.

19. Butler T, Milner L. The 2001 Inmate Health Survey. Sydney: NSW Corrections Health Service, ISBN: 07347 3560X 2003.

20. Gesch B, Hammond S, Hampson S, Eves A, Crowder M. Influence of supplementary vitamins, minerals and essential fatty acids on the antisocial behaviour of young adult prisoners: randomised, placebo-controlled trial. $\mathrm{Br} \mathrm{J}$ Psychiatry 2002; 181: 22-8.

21. Hibbeln JR, Nieminen LRG, Lands WEM. Increasing homicide rates and linoleic acid consumption among five western countries, 1961-2000. Lipids 2004; 39(12): 1207-13.

22. Harer MD, Langan NP. Gender differences in predictors of prison violence: Assessing the predictive validity of a risk classification system. Crime Delinq 2001; 47(4): 513-36.

23. Corben S. Assaults and fights in NSW correctional centres. Sydney: New South Wales Department of Corrective Services, 2002.

24. Hewitt JD, Poole ED, Regoli RM. Self-reported and observed rule-breaking in prison: A look at disciplinary response. The Justice Quarterly 1984:1(3): 437-47.

25. European Committee for the Prevention of Torture and Inhuman or Degrading Treatment or Punishment (CPT). The CPT standards. Council of Europe, 2003. Available at: www. cpt.coe.int/EN/docsstandards.htm. Accessed 7 June 2006.

26. Butler T, Kariminia A, Bond J, Trevathan L. Injury surveillance in the New South Wales prison system. Australian Journal of Health Promotion 2004; 15: 146-9. 숭 